\title{
Is open repair still the standard for the descending and thoracoabdominal aorta?
}

\author{
Anthony L. Estrera, MD
}

\footnotetext{
From the Department of Cardiothoracic and Vascular Surgery, The University of Texas Medical School at Houston, Memorial Hermann Heart \& Vascular Institute, Houston, Tex.

Disclosures: A.L.E. is a consultant for WL Gore \& Associates Inc.

Received for publication Sept 1, 2015; accepted for publication Sept 2, 2015; available ahead of print Oct 6, 2015. Address for reprints: Anthony L. Estrera, MD, Department of Cardiothoracic and Vascular Surgery, The University of Texas Medical School at Houston, 6400 Fannin St, Suite 2850, Houston, TX 77030 (E-mail: Anthony.L. Estrera@uth.tmc.edu).

J Thorac Cardiovasc Surg 2016;151:1232-4

$0022-5223 / \$ 36.00$

Copyright (c) 2016 by The American Association for Thoracic Surgery

http://dx.doi.org/10.1016/j.jtcvs.2015.09.011
}

In 1982, at the annual International Society for Cardiovascular Surgery conference, Dr Crawford ${ }^{1}$ delivered the presidential address titled, "Aortic Aneurysm: A Multifocal Disease," in which they reported results on 191 patients (from a total of 1510) with multiple thoracic aneurysms. In this series, which spanned from 1956 to 1982, they outlined many important principles from their experience, including insights into staging of repairs, recognition of recurrences - especially in patients with Marfan syndromeand the importance of comprehensive screening. They concluded that "aortic aneurysmal disease is multifocal and needed total aortic screening; best results are obtained by complete replacement of all disease." 1 Although very simple and intuitive, these remarks, made more than 30 years ago, remain pertinent and relevant today. Or do they?

We know now that thoracic aortic disease may occur in concurrent locations in as many as $20 \%$ of cases and that complete aortic evaluation should be considered for most. But the question is, does the thoracic aorta need to be replaced in all cases or is endovascular exclusion enough? Is endovascular repair the new standard?

In this edition of the Journal, Coselli and colleagues ${ }^{2}$ report the largest series of thoracoabdominal aortic repairs ever amassed. From 1986 to 2014, 3264 repairs of the thoracoabdominal aorta were performed. The early mortality was commendable (7\%), and adverse events, defined as death, paraplegia, stroke, and renal failure at discharge, were just $14 \%$. Paraplegia occurred in 5\%, stroke occurred in $2 \%$, and renal failure occurred in $6 \%$ of cases, all very respectable. As expected, determinants of early mortality were increasing age, renal dysfunction, extent II and IV aneurysm, rupture, involvement of the visceral vessels, and increasing clamp time. Ten- and 20-year actuarial survivals were just $37 \%$ and $10 \%$, respectively, as would be expected for this patient population. Remarkable was the fact that freedom from repair failure at 20 years was $91 \%$. As a response in the discussion, it was interesting that little significant improvement in outcomes was

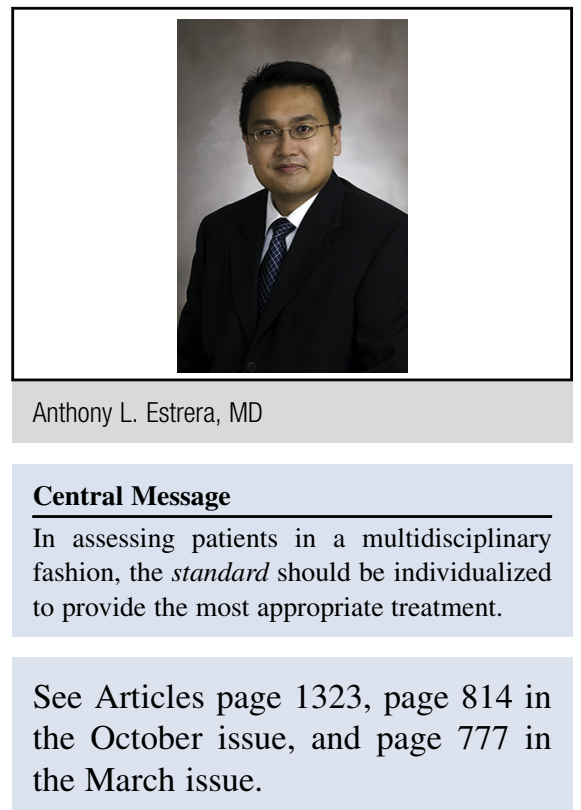

See Editorial Commentaries page 1339 and page 786 in the March issue.

See Editorial page 616 in the March issue.

observed over the study period, suggesting that it would be difficult to improve such results for open repair much further.

With the introduction of the stent graft to the abdominal and thoracic aorta, an endovascular revolution was launched. ${ }^{3,4}$ This technology has been disruptive, because it has allowed treatment to a broader population who may not have had other options. The US Food and Drug Administration approved the first device for the thoracic aorta in 2005 and expanded its use to include all disorders of the thoracic aorta in 2014. A gradual increase in total aortic procedures performed and a shift from open to endovascular repair have occurred. ${ }^{5}$ Over the past decade, no situation has demonstrated this shift better than endovascular repair of traumatic aortic injuries. ${ }^{6}$ Despite limited late results with thoracic endovascular aortic repair for traumatic aortic injuries, the improved early survival has justified its dramatic adoption for this pathology. ${ }^{7}$ Likewise, endovascular treatment is now considered first-line treatment for other acute aortic syndromes, 
such as thoracic aortic rupture and complicated acute type B aortic dissection. ${ }^{8,9}$ Of note, this edition of the Journal also features a study from the Cornell group, who reported 100 consecutive open repairs for thoracic aortic rupture (descending and thoracoabdominal) with an early mortality of $14 \%$, paraplegia of $5 \%$, need for tracheostomy of $19 \%$, and need for dialysis of $11 \% .{ }^{10}$ Despite these outstanding results, however, endovascular repair will likely continue to be the treatment of choice for rupture, because many centers do not have the expertise to perform open repair or the time to transfer to a center that does. Technology, as it relates to the endovascular stent graft, has made it easier on both the patient and surgeon to repair the thoracic aorta and has broadened its applicability across subspecialties. Now, one does not have to be Crawford or Cohen to repair the thoracic aorta with good results.

With the expanded indications for thoracic endovascular aortic repair, it can be easy to just perform the procedure without too much thought and effort. At the 2012 American Association for Thoracic Surgery Aortic Symposium, Dr Miller ${ }^{11}$ outlined some very important points by suggesting that the indications for endovascular repair should be better defined and that "just because we can treat doesn't necessarily mean we should treat." At the time, his argument was based primarily on administrative data of large cohorts, such as the National Inpatient Survey and the Medicare database, which was compelling, but, unfortunately, not of the rigor of randomized controlled trials. At any rate, he raised very important points about the futility of prolonging life without improvement in quality of life, and that without close and careful scrutiny of new technologies, innovation in the end would be threatened. It is only through proper self-monitoring, quality control, and wellconstructed, long-term studies that advancements can be made.

In view of these important points, continuing studies on the durability of endovascular repair have become critical. Although midterm results (3-5 years) are important, we should now focus on including 10 - and even 20 -year outcomes to truly determine treatment effectiveness. Several reports out to 20 years are now available with open repair, including the report from Coselli and colleagues, ${ }^{2}$ most of which tout the primary advantage of durability and "freedom from repair failure." ${ }^{2,13}$ Little is currently available for endovascular repair of the thoracic aorta. ${ }^{14}$ But does a stent graft need to last more than 10 years? In the end, this all hinges on the individual patient. This is why an individualized standard should be provided to each patient and his/her specific situation.

Endovascular therapies are, without a doubt, less invasive and less stressful physiologically to the patient compared with open repair. But this, for now, comes at the cost of reduced durability. Not all patients require 20 years of

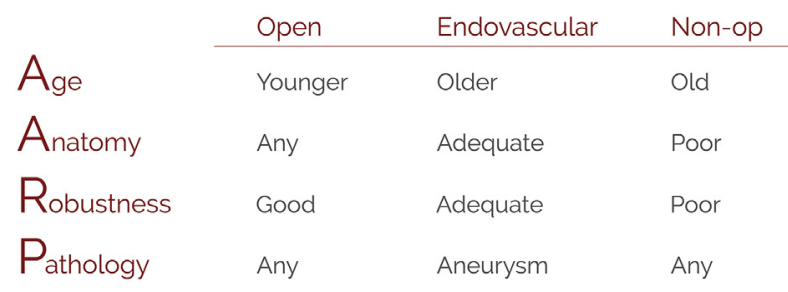

FIGURE 1. "Individualized standard" for aneurysm treatment.

durability, and thus the decision of what to do should be balanced with patient factors. Which factors are important remain undetermined, but recent studies have identified certain comorbidities that may preclude open repair. Some of these include age and renal, respiratory, and cardiac dysfunction.,13 For the foreseeable future, open repair will continue to be an important part in the treatment of the thoracic aorta, but, unlike during Crawford and Cohen's era-when only open repair was availablethe standard treatment is not limited to just one approach. Again, an individualized standard should be adopted. Certain conditions and situations should be considered for each therapeutic modality. This needs to be completely transparent because all options should be provided to each patient, including nonoperative management. In determining individualized standard for patients with thoracic aortic disease, we should consider the Age, Anatomy, Robustness, and Pathology (Figure 1).

1. Age should be considered on both a chronologic and a physiologic basis. Moreover, the patient's life expectancy likely may be a more critical determinant because younger patients ( $<60$ years) will require a more durable option.

2. Anatomy: The success of an endovascular intervention relies on the anatomy, including the integrity of the landing zone, length of the neck, angulation, and associated involvement of pertinent branch vessels, which could lead to endoleaks and organ malperfusion. Although each device has "Instructions for Use" as provided by the manufacturer, many devices have been applied in an "off-label" manner. Expanding the anatomy by using hybrid approaches may be applied-but only when consideration of all aspects of the individualized standard has been made. Although endovascular intervention may be considered for most cases, consideration should be made for open repair when anatomy does not allow.

3. Robustness refers to the individual predicted ability to withstand the stress of the intervention. Many factors have been considered, including comorbidities, such as renal dysfunction, but this also includes more subjective states, such as frailty and fitness. Unfortunately, few studies have been reported using parameters of frailty, and determining their significance in aortic surgery has yet to be well defined. 
4. Pathology: Differing pathologies will be amenable to certain interventions. Connective tissue disorders, such as Marfan syndrome, should be considered for open repair, because many of these patients are younger and the pathology of the aortic wall will always remain in question until replaced. This also includes chronic dissection because the mature dissecting flap and the distal retrograde flow will not allow consistent "remodeling."

Thus, when confronted with a complex thoracic aortic condition, these issues should be considered and discussed to provide the best therapeutic option to the patient. Ideally, this should occur in the presence of a multidisciplinary aortic team. This would allow all options to be implemented. Most important, the plan should be individualized and then presented to the patient.

In the end, the reports from Coselli and colleagues ${ }^{2}$ and Gaudino and colleagues ${ }^{10}$ emphasize the current relevance of open repair for the thoracoabdominal aorta in the era of the endovascular revolution and provide contemporary results to which endovascular therapies may be compared. But, is asking whether open surgery is still the standard the correct question? Declaring a standard implies competing technologies. In contrast, open and endovascular are truly complementary, because both can provide benefit to the patient. Therefore, in assessing the patient in a multidisciplinary fashion-considering age, anatomy, robustness, and pathology - the standard for the patient should be individualized to provide the most appropriate treatment. Currently, open repair does provide durability, but only time will tell if Crawford's ${ }^{1}$ original assertion-that the best results are obtained by complete replacement of all diseaseis correct.

\section{References}

1. Crawford ES, Cohen ES. Aortic aneurysm: a multifocal disease. Presidential address. Arch Surg. 1982;117:1393-400.

2. Coselli JS, Preventza O, de la Cruz KI, Cooley DA, Price MD, Green S, et al. Outcomes of 3264 thoracoabdominal aortic aneurysm repairs. Presented at: The American Association for Thoracic Surgery 2015 Annual Meeting; April 25-29, 2015; Seattle, WA. Available at: http://aats.org/annualmeeting/ProgramBooks/2015/1.cgi.

3. Parodi JC, Palmaz JC, Barone HD. Transfemoral intraluminal graft implantation for abdominal aortic aneurysms. Ann Vasc Surg. 1991;5:491-9.

4. Dake MD, Miller DC, Semba CP, Mitchell RS, Walker PJ, Liddell RP. Transluminal placement of endovascular stent-grafts for the treatment of descending thoracic aortic aneurysms. N Engl J Med. 1994;331:1729-34.

5. Scali ST, Goodney PP, Walsh DB, Travis LL, Nolan BW, Goodman DC, et al National trends and regional variation of open and endovascular repair of thoracic and thoracoabdominal aneurysms in contemporary practice. J Vasc Surg. 2011;53:1499-505.

6. DuBose JJ, Leake SS, Brenner M, Pasley J, O'Callaghan T, Luo-Owen X, et al. Contemporary management and outcomes of blunt thoracic aortic injury: a multicenter retrospective study. J Trauma Acute Care Surg. 2015;78:360-9.

7. Estrera AL, Gochnour DC, Azizzadeh A, Miller CC III, Coogan S, CharltonOuw KM, et al. Progress in the treatment of blunt thoracic aortic injury: 12year single-institution experience. Ann Thorac Surg. 2010;90:64-71.

8. Jonker FH, Trimarchi S, Verhagen HJ, Moll FL, Sumpio BE, Muhs BE. Metaanalysis of open versus endovascular repair for ruptured descending thoracic aortic aneurysm. J Vasc Surg. 2010;51:1026-32. 32.e1-32.e2.

9. Szeto WY, McGarvey M, Pochettino A, Moser GW, Hoboken A, Cornelius K, et al. Results of a new surgical paradigm: endovascular repair for acute complicated type B aortic dissection. Ann Thorac Surg. 2008;86:87-94.

10. Gaudino MF, Lau C, Minjal M, Girardi LN. Open repair of ruptured descending thoracic and thoracoabdominal aortic aneurysms in 100 consecutive cases. $J$ Thorac Cardiovasc Surg. 2015; 150:814-23.

11. Miller DC. Through the looking glass: the first 20 years of thoracic aortic stentgrafting. J Thorac Cardiovasc Surg. 2013;145:S142-8.

12. Estrera AL, Jan A, Sandhu H, Shalhub S, Medina-Castro M, Nguyen TC, et al. Outcomes of open repair for chronic descending thoracic aortic dissection. Ann Thorac Surg. 2015;99:786-94.

13. Estrera AL, Sandhu HK, Charlton-Ouw KM, Afifi RO, Azizzadeh A, Safi HJ. A quarter century of organ protection in open thoracoabdominal repair. Ann Surg. 2015;262:660-8.

14. van Bogerijen GH, Patel HJ, Williams DM, Yang B, Desika NL, Eliason JL, et al. Propensity adjusted analysis of open and endovascular thoracic aortic repair for chronic type B dissection: a twenty-year evaluation. Ann Thorac Surg. 2015;99: 1260-6. 